\title{
Comparison of Anterior Mitral Leaflet Repair Techniques with and without the Use of Chordal Replacement in Patients with Degenerative Mitral Valve Insufficiency
}

\author{
Ersin Kadiroğulları, ${ }^{1}$ Ömer Faruk Çiçek, ${ }^{2}$ Serkan Mola, ${ }^{3}$ Emre Yaşar, ${ }^{1}$ İbrahim Erkengel, ${ }^{3}$ \\ Adnan Yalçınkaya, ${ }^{4}$ Eren Günertem, ${ }^{3}$ Ferhat İkbaliafşar, ${ }^{3}$ Adem Diken, ${ }^{4}$ Sabit Kocabeyoğlu, ${ }^{3}$ \\ Gökhan Lafçı, ${ }^{3}$ Kerim Çağl1 ${ }^{3}$
}

\begin{abstract}
${ }^{1}$ Department of Cardiovascular Surgery, Mehmet Akif Ersoy Thoracic and Cardiovascular Surgery Training and Research Hospital, Istanbul, Turkey; ${ }^{2}$ Department of Cardiovascular Surgery, Selçuk University School of Medicine, Konya, Turkey; ${ }^{3}$ Department of Cardiovascular Surgery, Turkiye Yuksek Ihtisas Training and Research Hospital, Ankara, Turkey; ${ }^{4}$ Department of Cardiovascular Surgery, Hitit University School of Medicine, Çorum, Turkey
\end{abstract}

\section{ABSTRACT}

Background: The aim of our study was to compare the outcome of patients who underwent mitral valve anterior leaflet repair with and without chordal replacement for degenerative mitral valve insufficiency.

Methods: This study was conducted at our center between May 2006 and May 2013. The study included 125 patients with degenerative mitral valve insufficiency (64 males, 61 females; mean age 47 years, age range 16-78 years) who underwent mitral valve repair with anterior leaflet procedures. The patients were divided into 2 groups. Group A consisted of 56 patients with chordal replacement, and group B consisted of 69 patients with other repair techniques performed.

Results: No significant difference was determined between the 2 groups in mortality, recurrence, and reoperation rates. The mortality rate was $3.6 \%$ in group $\mathrm{A}$ and $1.4 \%$ in group B. During the follow-up period, 3 patients were reoperated on (mitral valve replacement) because of severe mitral valve insufficiency. Two of these patients were from group A (3.6\%), and the other was from group B (1.4\%). One patient in group A underwent intraoperative mitral valve replacement after unsuccessful chordal replacement. Fifty patients $(89.3 \%)$ in group A and 65 patients $(94.2 \%)$ in group B exhibited no or mild recurrence of mitral valve insufficiency.

Conclusion: Mitral valve repair in patients with degenerative mitral valve insufficiency resulting from anterior leaflet pathology is a safe procedure because of its durability and good long-term results. Despite the difficulty of the chordal replacement procedure, it may be used as an alternative technique for anterior mitral valve leaflet repair.

Received November 24, 2018; accepted December 21, 2018.

Correspondence: Ömer Faruk Çiçek, MD, Alaeddin Keykubat Yerleskesi, Selçuk Universitesi Tip Fakultesi, Kalp ve Damar Cerrabisi Anabilim Dali, 42075, Selçuklu, Konya, Turkey; +90-505-7721661; fax: +90-332-2416065 (e-mail: farux@hotmail.com).

\section{INTRODUCTION}

Mitral valve repair has many advantages over replacement in patients with mitral valve insufficiency [Sand 1987]. The most important of these advantages is reduced need for anticoagulation and thereby minimal risk of hemorrhage and thrombosis, lower risk of infective endocarditis, and preservation of left ventricular function [Goldsmith 2001].

The anterior mitral leaflet plays an important role in coaptation during mitral valve closure. Mitral valve insufficiencies associated with large mitral valve prolapse, annulus dilatation, and leaflet calcification are complex pathologies that require experience and are unforgiving [David 2005]. These complex mitral valve pathologies should be repaired in centers with high success and low mortality rates [Gammie 2009].

In recent years, improvements in suture materials and the accumulation of surgical experience have enabled the successful implementation of anterior mitral leaflet repair with chordal replacement [Kuntze 2008]. With favorable outcomes achieved in patients with chordal replacement, it is now considered a viable alternative to other repair techniques [David 2013].

In this study, we aimed to evaluate the reliability of anterior mitral leaflet repair with and without chordal replacement in patients with degenerative mitral valve insufficiency by analyzing postoperative rates of complications, mortality, reoperation, and recurrence of mitral valve insufficiency.

\section{MATERIALS AND METHODS}

The study included 125 patients (64 males, 61 females; mean age 47 years, range 16-78 years) who underwent mitral valve repair with anterior leaflet procedures because of degenerative mitral valve insufficiency. All surgeries were performed between May 2006 and May 2013 by the single surgical team in the Turkiye Yüksek Ihtisas Hospital in Ankara, Turkey. Patients who underwent emergency surgery, reoperation, and surgery due to ischemic mitral insufficiency, congenital mitral insufficiency, and mitral insufficiency associated with infective 
Table 1. Echocardiographic Grading of Mitral Valve Insufficiency

\begin{tabular}{lcccc} 
Mitral Insufficiency Grade & Mitral Regurgitation Volume $(\mathrm{mL} /$ Stroke) & Effective Regurgitation Area $\left(\mathrm{cm}^{2}\right)$ & Vena Contracta Width $(\mathrm{cm})$ & Regurgitation Jet Area $\left(\mathrm{cm}^{2}\right)$ \\
\hline None & 0 & 0 & 0 & 0 \\
Mild & $<30$ & $<0.20$ & $<0.30$ & $<4$ \\
Moderate & $30-59$ & $0.20-0.39$ & $0.30-0.69$ & $4-10$ \\
Severe & $>60$ & $>0.40$ & $>0.7$ & $>10$
\end{tabular}

endocarditis were excluded from the study. The patients were divided into 2 groups: group A consisted of 56 patients (45\%) who underwent anterior chordal replacement, whereas group B consisted of 69 patients (55\%) who did not have chordal replacement but underwent other repair techniques such as chordal shortening, secondary chordal transfer, chordal transfer from the posterior leaflet, cleft repair, and triangular resection. The mean follow-up period was $24.4 \pm 16.8$ months (range 1-58 months). The study was approved by the hospital ethics committee.

The patients' demographic, preoperative, and postoperative data were collected from the hospital database. Echocardiography was performed using a Vivid 7 Dimension device (GE Medical Systems, Horten, Norway). Severity of mitral valve insufficiency was classified on the basis of echocardiographic-findings criteria from $0-4$ ( 0 , none; 1 , mild; 2 , moderate; 3 , moderate to severe; 4 , severe insufficiency) [Zoghbi 2003]. Volume of mitral regurgitation, effective regurgitation orifice area, and vena contracta were recorded during echocardiographic examination (Table 1).

\section{Surgical Technical}

All operations were carried out under general anesthesia with intraoperative transesophageal echocardiography (TEE). All patients were operated on through a median sternotomy, on cardiopulmonary bypass with moderate hypothermia. Antegrade and retrograde cold blood cardioplegia was used for diastolic arrest. Mitral valve interventions were performed either through a left atriotomy or via a transseptal approach.

During chordal replacement, neochordae lengths were determined using a length of non-elongated chord, adjacent chord, or secondary chord. Neochordae were made from 4-0 and 5-0 expanded polytetrafluoroethylene (ePTFE) suture (Gore-Tex; W. L. Gore \& Associates, Flagstaff, AZ, USA). Chordal shortening was done by separating the elongated chord, joining it to an adjacent secondary chord, and folding the joined chord into the leaflet. Native chordal transfer was done in selected patients whose secondary chordae were suitable for transfer to primary position.

Chordal transfer from posterior leaflet to anterior leaflet was performed in patients whose posterior leaflet chorda location on their papillary muscle was suitable for transfer to the anterior leaflet. In patients who underwent ring annuloplasty, Carpentier-Edwards Physio and Physio II Annuloplasty Rings (Edwards Lifesciences, Irvine, CA, USA) were used as semiflexible rings, and St. Jude Medical Rigid Saddle Ring (St. Jude Medical, St Paul, MN) was used as a rigid ring.
Left atrial appendage internal ligation was applied in all patients, and atrial reduction was performed in patients with left atrial diameter over $5.0 \mathrm{~cm}$. The area between the left and right pulmonary vein and the posterior wall of the left atrium was sutured vertically. Ring annuloplasty was done in all patients with tricuspid annulus greater than $40 \mathrm{~mm}$. Concomitant coronary artery bypass grafting was performed in patients who had critical coronary lesions.

Intraoperative TEE was performed in all patients after discontinuing cardiopulmonary bypass. If a patient still had moderate or severe mitral insufficiency after reconstruction according to intraoperative TEE, it was decided to do reexploration of the mitral valve.

\section{Follow-up}

For all patients, postoperative control TTE was performed by the same cardiologist and evaluated by the same surgeon before discharge from hospital. Echocardiographic findings recorded during the follow-up period were included in our study. End points of the study were reoperation due to severe mitral valve insufficiency or mortality at any time during the follow-up period. Deaths occurring within the first 30 postoperative days were accepted as early mortality, whereas deaths occurring more than 30 days postoperatively were considered late mortality.

\section{Statistical Analysis}

Statistical analysis was performed using the SPSS (version 16.0; SPSS Inc., Chicago, IL, USA) package program. Continuous variables were expressed as mean \pm standard deviation. Categorical variables were given as percentages. Statistical differences between the patients in the study groups were investigated using the $t$ test and the Mann-Whitney $U$ test for continuous variables. Categorical data were evaluated with the chi-square test. $P$ values less than .05 were considered statistically significant.

\section{RESULTS}

Our study consisted of patients who underwent mitral valve repair with anterior mitral leaflet procedures because of degenerative mitral valve insufficiency. Group A consisted of 56 patients $(45 \%)$ who underwent chordal replacement and group B consisted of 69 patients (55\%) whose anterior leaflet repair was done using techniques other than chordal replacement. The mean follow-up period was $24.4 \pm 16.8$ months (range, 
Table 2. Demographic Data of the Study Population*

\begin{tabular}{|c|c|c|c|c|}
\hline Follow-up period (months) & $24.4 \pm 16.8$ & $19.4 \pm 14.0$ & $28.2 \pm 17.9$ & .007 \\
\hline Sex, male & $64(51.2 \%)$ & $30(53.6 \%)$ & $34(49.3 \%)$ & .633 \\
\hline NYHA classification & $2.1 \pm 0.4$ & $2.1 \pm 0.4$ & $2.1 \pm 0.5$ & .779 \\
\hline HT & $26(20.8 \%)$ & $13(23.2 \%)$ & $13(18.8 \%)$ & .549 \\
\hline DM & $9(7.2 \%)$ & $6(10.7 \%)$ & $3(4.3 \%)$ & .171 \\
\hline Smoking & $16(12.8 \%)$ & $6(10.7 \%)$ & $10(14.5 \%)$ & .529 \\
\hline COPD & $23(18.4 \%)$ & $13(23.2 \%)$ & $10(14.5 \%)$ & .211 \\
\hline CVD & $1(0.8 \%)$ & $0(0 \%)$ & $1(1.4 \%)$ & .366 \\
\hline MI (grade) & $3.5 \pm 0.53$ & $3.5 \pm 0.57$ & $3.5 \pm 0.51$ & .573 \\
\hline EF (\%) & $58.7 \pm 7.5$ & $58.5 \pm 7.1$ & $58.8 \pm 7.8$ & .836 \\
\hline $\operatorname{LVEDD}(\mathrm{cm})$ & $5.5 \pm 0.64$ & $5.6 \pm 0.64$ & $5.4 \pm 0.63$ & .196 \\
\hline $\operatorname{LVESD}(\mathrm{cm})$ & $3.9 \pm 0.6$ & $3.97 \pm 0.58$ & $3.82 \pm 0.63$ & .165 \\
\hline PAP $(\mathrm{mmHg})$ & $43.4 \pm 7.8$ & $43.3 \pm 8.8$ & $43.5 \pm 6.9$ & .923 \\
\hline $\mathrm{LA}(\mathrm{cm})$ & $4.6 \pm 0.55$ & $4.68 \pm 0.62$ & $4.5 \pm 0.48$ & .145 \\
\hline
\end{tabular}

*Group A: patients with chordal replacement in anterior leaflet; group B: patients without chordal replacement in anterior leaflet. Data (except P values) given as mean \pm standard deviation or $\mathrm{n}(\%)$. AF, atrial fibrillation; BMI, body mass index; COPD, chronic obstructive pulmonary disease; CRF, chronic renal failure; CVD, cerebrovascular disease; DM, diabetes mellitus; EF, ejection fraction; HT, hypertension; LVEDD, left ventricular end-diastolic diameter; LA, left atrial diameter; LVESD, Left ventricular end-systolic diameter; MI, mitral insufficiency; NYHA, New York Heart Association; PAP, pulmonary artery pressure.

2-58) months. The patients' demographic data are summarized in Table 2. Follow-up was significantly longer in group B than in group $\mathrm{A}(P=.007)$. There were no statistically significant differences between the groups in terms of age, gender, functional lung capacity, hypertension, chronic obstructive lung disease, cerebral vascular events, smoking, or chronic kidney failure. The prevalence of preoperative atrial fibrillation $(\mathrm{AF})$ was significantly higher in group $\mathrm{A}(P=.001)$. There was no statistically significant difference between the groups in terms of preoperative echocardiography findings, especially mitral valve insufficiency and ejection fractions $(\mathrm{EF})$.

Operative data pertaining to the 2 groups are shown in Table 3. No statistically significant difference was found between the 2 groups in terms of cross-clamping time and cardiopulmonary bypass time $(P=.162$ and $P=$ .245 , respectively).

In group B, chordal shortening was performed in 24 patients, secondary chordal transfer in 19 patients, posterior chordal transfer in 5 patients, cleft repair in 24 patients, and triangular resection in 5 patients. A total of 77 repair techniques were utilized in the 69 patients in group B.

Patients with other pathologies in addition to mitral valve insufficiency were also included. In these patients, tricuspid valve annuloplasty was conducted significantly more often in group A patients $(P=.004)$ (Table 3$)$.

Postoperative data are shown in Table 4. There were no statistically significant differences between the groups in terms of inotropic requirement $(5 \mu \mathrm{g} / \mathrm{kg}$ per minute or more dopamine or dobutamine infusion within the first 24 hours postoperatively) or intra-aortic balloon pump therapy $(P=$ .795 and $P=.366$, respectively). There was no significant difference between the groups in terms of arrhythmias $(P=.298)$, although 8 patients developed bradycardia because of heart block and required temporary pacing. Permanent pacemakers were not implanted in any of the patients before discharge.

There were no statistically significant differences between the 2 groups in terms of extubation time, intensive care unit stay, or hospital stay $(P=.343, .266$, and .812 , respectively). Drainage volumes in the 2 groups were similar $(P=.834)$.

Three patients underwent revision because of bleeding in the postoperative follow-up period (1 patient in group A). There was no statistically significant difference between the groups in terms of bleeding $(P=.485)$.

There were also no significant differences between the 2 groups in terms of renal damage $(1-\mathrm{mg} / \mathrm{dL}$ increase in creatine), pulmonary complications (pneumonia, acute 
Table 3. Operative Data of the Study Population*

\begin{tabular}{|c|c|c|c|}
\hline & $\begin{array}{l}\text { Group A } \\
(n=56)\end{array}$ & $\begin{array}{l}\text { Group B } \\
(n=69)\end{array}$ & $P$ \\
\hline Cross-clamping time & $102.7 \pm 21.9$ & $96.8 \pm 29.1$ & .162 \\
\hline CPB time & $121.9 \pm 18.6$ & $126.6 \pm 24.9$ & .245 \\
\hline Transseptal approach & $9(16 \%)$ & $7(10.1 \%)$ & .324 \\
\hline \multicolumn{4}{|l|}{ Annuloplasty procedure } \\
\hline Semiflexible ring & $32(57.1 \%)$ & $46(66.7 \%)$ & .272 \\
\hline Rigid ring & $23(41.1 \%)$ & $18(26.1 \%)$ & .075 \\
\hline Teflon strip & $1(1.8 \%)$ & $5(7.2 \%)$ & .223 \\
\hline Average ring size & $29.4 \pm 2.1$ & $29.3 \pm 1.86$ & .778 \\
\hline \multicolumn{4}{|l|}{ Additional procedures } \\
\hline Coronary artery bypass grafting & $4(7 \%)$ & $9(13 \%)$ & .392 \\
\hline Aortic valve surgery & $7(12.5 \%)$ & $12(17.4 \%)$ & .786 \\
\hline Tricuspid ring annuloplasty & $33(58.9 \%)$ & $23(33 \%)$ & .004 \\
\hline Atrial septal defect & $6(10.7 \%)$ & $13(18.8 \%)$ & .208 \\
\hline Left atrial volume reduction & $19(19 \%)$ & $17(24.2 \%)$ & .234 \\
\hline \multicolumn{4}{|l|}{ Anterior leaflet repair techniques } \\
\hline Chordal replacement & 56 & - & - \\
\hline Chordal shortening & - & 24 & - \\
\hline Secondary chordal transfer & - & 19 & - \\
\hline $\begin{array}{l}\text { Chordal transfer from posterior } \\
\text { leaflet }\end{array}$ & - & 5 & - \\
\hline Cleft repair & - & 24 & - \\
\hline Triangular resection & - & 5 & - \\
\hline
\end{tabular}

*Group A: patients with chordal replacement in anterior leaflet; group B: patients without chordal replacement in anterior leaflet. Data (except $P$ values) given as mean \pm standard deviation or $\mathrm{n}(\%)$. CPB, cardiopulmonary bypass.

respiratory distress syndrome, pulmonary embolism), surgical site infections, or neurological changes $(P=.265, .286, .826$, and 1.0, respectively) (Table 4).

Patients who had recurrent mitral valve insufficiency during follow-up were compared in terms of reoperation and mortality (Table 5). Three patients $(2.4 \%)$ died in total, 1 in the early postoperative period and 2 in the late postoperative period. Early and late mortality rates were not statistically different when compared between the groups $(P=.265$ and .882 , respectively). The patient with early mortality was in group A and died on postoperative day 5 because of respiratory failure resulting in aspiration pneumonia. Of the 2 patients with late mortality, 1 was in group A, and the cause of death was pulmonary thromboembolism on postoperative day 60 , whereas the other patient was in group B and was lost 180 days after surgery because of cardiac failure.

There was no significant difference between the 2 groups in the distribution of patients with recurrent mitral valve
Table 4. Postoperative Data and Complications of the Study Population*

\begin{tabular}{lccc}
\hline & $\begin{array}{c}\text { Group A } \\
(\mathrm{n}=56)\end{array}$ & $\begin{array}{c}\text { Group B } \\
(\mathrm{n}=69)\end{array}$ & $P$ \\
\hline Inotrope requirement & $7(12.5 \%)$ & $10(14.5 \%)$ & .795 \\
IABP & $0(0 \%)$ & $1(1.4 \%)$ & .366 \\
Arrhythmia & $5(8.9 \%)$ & $3(4.3 \%)$ & .298 \\
Extubation time (hours) & $10.8 \pm 3.2$ & $10.3 \pm 3.3$ & .343 \\
ICU stay (days) & $1.3 \pm 0.5$ & $1.2 \pm 0.4$ & .266 \\
Hospital stay (days) & $5.96 \pm 1.23$ & $5.91 \pm 1.04$ & .812 \\
Drainage (mL) & $360 \pm 390$ & $350 \pm 350$ & .834 \\
Revision due to bleeding & $1(1.8 \%)$ & $2(2.8 \%)$ & .485 \\
Acute kidney failure & $1(1.8 \%)$ & $0(0 \%)$ & .265 \\
Wound infection & $2(3.6 \%)$ & $3(4.3 \%)$ & .726 \\
Pulmonary complications & $2(3.6 \%)$ & $3(4.39 \%)$ & .826 \\
Neurologic complications & $0(0 \%)$ & $0(0 \%)$ & 1.000 \\
\hline
\end{tabular}

*Group A: patients with chordal replacement in anterior leaflet; group B: patients without chordal replacement in anterior leaflet. Data (except $\mathrm{P}$ values) given as mean \pm standard deviation or $n(\%) . I A B P$, intra-aortic balloon pump; ICU, intensive care unit.

insufficiency $(P=.265)$. Of the 56 patients in group $\mathrm{A}, 49$ $(87.5 \%)$ showed no recurrence, $1(1.8 \%)$ had mild mitral valve insufficiency, and $3(5.4 \%)$ patients had moderate mitral valve insufficiency. Of the 69 patients in group B, $62(89.9 \%)$ had no recurrence, $3(4.3 \%)$ had mild mitral valve insufficiency, and 1 $(1.4 \%)$ had moderate mitral valve insufficiency (Table 5).

Mitral valve replacement (MVR) was performed in 4 $(3.2 \%)$ of 5 patients $(4 \%)$ with severe mitral regurgitation. In $1(0.8 \%)$ of these patients, severe mitral valve insufficiency was detected intraoperatively, and the valve tissue was deemed too fragile to repair; therefore, MVR was preferred. Of the 3 patients who underwent late MVR, $2(2.4 \%)$ were in group $\mathrm{A}$, and the other was in group B. The fifth patient who developed severe mitral valve insufficiency died because of heart failure on postoperative day 180 .

Comparisons of the preoperative and postoperative rhythms, functional capacities, and echocardiographic data of the patients revealed significant differences in both groups in all echocardiographic parameters except EF (Table 6).

\section{DISCUSSION}

The benefits of mitral valve repair over MVR in patients with mitral valve insufficiency are well established and include lower morbidity and mortality rates, better preservation of left ventricle function, and less risk of thromboembolic events and endocarditis [Jokinen 2007].

Although surgeons obtain good results with all etiologies of mitral valve insufficiency, success rates are highest in 
Table 5. Postoperative Mortality, Recurrence of Mitral Valve Insufficiency, and Conversion to Early and Late MVR: Results of the Study Population*

\begin{tabular}{|c|c|c|c|c|}
\hline \multicolumn{5}{|l|}{ Mortality } \\
\hline Early mortality & $1(0.8 \%)$ & $1(1.8 \%)$ & $0(0 \%)$ & .265 \\
\hline Late mortality & $2(1.6 \%)$ & $1(1.8 \%)$ & $1(1.4 \%)$ & .882 \\
\hline None & $111(88.8 \%)$ & 49 (87.5\%) & $62(89.9 \%)$ & .265 \\
\hline Mild & $4(3.2 \%)$ & $1(1.8 \%)$ & $3(4.3 \%)$ & \\
\hline Moderate & $4(3.2 \%)$ & $3(5.4 \%)$ & $1(1.4 \%)$ & \\
\hline Severe & $5(4 \%)$ & $3(5.4 \%)$ & $2(2.9 \%)$ & \\
\hline Intraoperative MVR & $1(0.8 \%)$ & $1(1.8 \%)$ & $0(0 \%)$ & .265 \\
\hline
\end{tabular}

*Group A: patients with chordal replacement in anterior leaflet; group B: patients without chordal replacement in anterior leaflet. Data (except $\mathrm{P}$ values) given as $\mathrm{n}(\%)$. MI, mitral insufficiency, MVR, mitral valve replacement.

repairs of degenerative mitral valve disease [DiBardino 2010]. A study comparing 36 years of repair outcomes from patients with degenerative mitral valve disease and patients with rheumatic and functional mitral valve diseases revealed that the 30 -year survival rate was $52 \%$ in degenerative disease, $39 \%$ in rheumatic disease, and $0 \%$ in functional mitral insufficiency. This emphasizes that mitral valve repair can be performed safely in cases with degenerative etiology.

Posterior prolapse is most common in degenerative mitral valve insufficiency, though the incidence of anterior and bileaflet involvement is also considerable [Braunberger 2001]. Mitral valve anterior leaflet repair surgery is rather complicated and more complex than posterior leaflet repair [Gillinov 2008]. This is because the anterior leaflet plays a major role in the main closure mechanism of the mitral valve and coaptation [Mohty 2001]. A complicating factor in anterior mitral leaflet repair is the inability to make resections as large as those made in the posterior leaflet, and this limitation has been the main impetus for the emergence of different repair techniques [Okada 2012]. As a result of these techniques, a growing number of studies report favorable outcomes in anterior leaflet repair, comparable to those of posterior leaflet repair [Castillo 2014].

There have been many studies comparing anterior mitral valve repair techniques [Smedira 1996]. With Robert Frater's introduction of Gore-Tex ePTFE suture material for chordal replacement, the chordal replacement technique has become a viable alternative to other repair techniques [Frater 1990; Gan 2008]. The main problems during the chordal replacement technique include Gore-Tex suture's lack of flexibility and difficulty in adjusting the lengths of the neochordae [David 1998; Calafiore 2006]. In a study by Philips et al comparing mitral valve anterior chordal replacement with chordal shortening techniques, chordal shortening was reported to be risky for reoperations, and it was emphasized that chordal replacement was a safe option in these cases [Phillips 2000].

In our study, patients with degenerative mitral valve insufficiency were treated using anterior leaflet repair procedures. In the mean follow-up period of 24 months, the number of patients with no or mild mitral valve insufficiency was 115 of 125 (92.0\%). This rate did differ significantly between patients with chordal replacement and those repaired using other techniques ( $89.3 \%$ and $94.2 \%$, respectively).

One patient treated with chordal replacement was returned to MVR intraoperatively after detection of mitral regurgitation, and another 3 patients underwent MVR during followup because of severe mitral valve insufficiency. Reoperation was not required in 121 of $125(96.8 \%)$ of our patients. There are many risk factors associated with reoperation. One of the largest patient series reported on this topic revealed that numerous factors related to the mitral valve repair techniques and the mitral valve itself are associated with reoperation [Dumont 2007]. Repair-related causes included detachment of sutures, systemic anterior motion, hemolysis, and failed surgery. Valve-related factors included progression of primary valvular disease and infective endocarditis. In the present study, recurrent severe mitral insufficiency developed in 1 patient in the chordal replacement group because of suture detachment and in 3 other patients because of infection. Those patients underwent secondary MVR.

Previous studies have reported varying mortality rates for mitral valve repair. Gillinov's anterior leaflet approach yielded a 10-year survival rate of $83 \%$ [Gillinov 2008]. Castillo and Adams reported 1-year and 7-year survival rates of $98 \%$ and $88 \%$, respectively, with an early mortality rate of $1 \%$ [Castillo 2014]. Morumoto et al reported 10-year and 15-year survival rates of $95 \%$ and $88 \%$, respectively [Morimoto 2008]. In our study, the mortality rate for all anterior leaflet approaches was 
Table 6. Comparison of Preoperative and Postoperative Data for Each Group*

\begin{tabular}{|c|c|c|c|c|c|c|}
\hline & Preoperative & Postoperative & $P$ & Preoperative & Postoperative & $P$ \\
\hline $\mathrm{AF}$ & 17 (30.4\%) & $4(7.3 \%)$ & .002 & $5(7.2 \%)$ & $1(1.5 \%)$ & .095 \\
\hline MI (grade) & $3.5 \pm 0.5$ & $0.8 \pm 0.7$ & .001 & $3.4 \pm 0.5$ & $1.0 \pm 0.5$ & .001 \\
\hline NYHA classification & $2.1 \pm 0.4$ & $1.0 \pm 0.2$ & .001 & $2.1 \pm 0.5$ & $1.0 \pm 0.1$ & .001 \\
\hline PAP $(\mathrm{mmHg})$ & $43.3 \pm 8.7$ & $34.4 \pm 7.1$ & .001 & $43.5 \pm 6.9$ & $31.2 \pm 4.3$ & .001 \\
\hline LVEDD $(\mathrm{mm})$ & $5.5 \pm 0.6$ & $5.1 \pm 0.6$ & .001 & $5.4 \pm 0.6$ & $4.86 \pm 0.6$ & .001 \\
\hline $\operatorname{LVESD}(\mathrm{mm})$ & $3.9 \pm 0.6$ & $3.6 \pm 0.6$ & .001 & $3.8 \pm 0.6$ & $3.5 \pm 0.6$ & .001 \\
\hline $\mathrm{LA}(\mathrm{cm})$ & $4.6 \pm 0.6$ & $4.4 \pm 0.6$ & .008 & $4.5 \pm 0.4$ & $4.0 \pm 0.5$ & .001 \\
\hline
\end{tabular}

*Group A: patients with chordal replacement in anterior leaflet; group B: patients without chordal replacement in anterior leaflet. Data (except P values) given as mean \pm standard deviation or $n(\%)$. AF, atrial fibrillation; EF, ejection fraction; LA, left atrial diameter; LVEDD, left ventricular end-diastolic diameter; LVESD, left ventricular end-systolic diameter; MI, mitral insufficiency; NYHA, New York Heart Association; PAP, pulmonary artery pressure.

2.4\%. Two of these patients were in the chordal replacement group, and 1 death occurred in the early postoperative period. There was no difference between early and late mortality rates between the 2 groups.

\section{Limitations}

The patient population included in this study was small and heterogeneous, and the follow-up period was relatively short. In addition, there was a statistically significant difference between the 2 study groups in terms of follow-up time because the chordal replacement technique was introduced into our clinical practice later than the other techniques. The accumulation of cases will enable the formation of more specific patient groups (anterior, posterior, bileaflet) for future analyses. This will allow the inclusion of other etiologies of mitral valve disease other than degenerative in our later studies. On the other hand, outcomes after complex procedures such as chordal replacement are very difficult to generalize because of surgical and institutional-technical differences.

Mitral valve anterior leaflet repair techniques are difficult; therefore, the choice of repair technique for specific pathology is crucial. The durability of the mitral valve after repair can be enhanced by preserving leaflet surface area, ensuring a large coaptation area, and properly adjusting the posterior leaflet height. Moreover, improvement in suture materials, the use of annuloplasty rings, and increased surgical experience lead to better outcomes of anterior mitral leaflet repair.

\section{REFERENCES}

Braunberger E, Deloche A, Berrebi A, et al. 2001. Very long-term results (more than 20 years) of valve repair with Carpentier's techniques in nonrheumatic mitral valve insufficiency. Circulation 104(12 suppl 1):I8-11.

Calafiore AM, Di Mauro M, Iacò AL, et al. 2006. Overreduction of the posterior annulus in surgical treatment of degenerative mitral regurgitation. Ann Thorac Surg 81:1310-6.

Castillo JG, Anyanwu AC, El-Eshmawi A, Adams DH. 2014. All anterior and bileaflet mitral valve prolapses are repairable in the modern era of reconstructive surgery. Eur J Cardiothoracic Surg 45:139-45; discussion 145.

David TE, Armstrong S, Ivanov J. 2013. Chordal replacement with polytetrafluoroethylene sutures for mitral valve repair: a 25 -year experience. J Thorac Cardiovasc Surg 145:1563-9.

David TE, Ivanov J, Armstrong S, Christie D, Rakowski H. 2005. A comparison of outcomes of mitral valve repair for degenerative disease with posterior, anterior, and bileaflet prolapse. J Thorac Cardiovasc Surg 130:1242-9.

David TE, Omran A, Armstrong S, Sun Z, Ivanov J. 1998. Long-term results of mitral valve repair for myxomatous disease with and without chordal replacement with expanded polytetrafluoroethylene sutures. J Thorac Cardiovasc Surg 115:1279-85; discussion 1285-6.

DiBardino DJ, ElBardissi AW, McClure RS, Razo-Vasquez OA, Kelly NE, Cohn LH. 2010. Four decades of experience with mitral valve repair: analysis of differential indications, technical evolution, and longterm outcome. J Thorac Cardiovasc Surg;139:76-83; discussion 83-4.

Dumont E, Gillinov AM, Blackstone EH, et al. 2007. Reoperation after mitral valve repair for degenerative disease. Ann Thorac Surg 84:444-50; discussion 450 .

Frater RW, Vetter HO, Zussa C, Dahm M. 1990. Chordal replacement in mitral valve repair. Circulation $82(5$ suppl):IV125-30.

Gammie JS, Sheng S, Griffith BP, et al. 2009. Trends in mitral valve surgery in the United States: results from the Society of Thoracic Surgeons Adult Cardiac Surgery Database. Ann Thorac Surg 87:1431-7; discussion 1437-9.

Gan HL, Zhang JQ, Wang SX, et al. 2008. [Repair of anterior leaflet mitral valve prolapse: the comparison between chordal replacement and chordal shortening]. Zhonghua Wai Ke Za Zhi 46:1727-9. Chinese.

Gillinov AM, Blackstone EH, Alaulaqi A, et al. 2008. Outcomes after repair of the anterior mitral leaflet for degenerative disease. Ann Thorac Surg 86:708-17. 
Goldsmith IRA, Lip GYH, Patel RL. 2001. A prospective study of changes in the quality of life of patients following mitral valve repair and replacement. Eur J Cardiothoracic Surg 20:949-55.

Jokinen JJ, Hippeläinen MJ, Pitkänen OA, Hartikainen JEK. 2007. Mitral valve replacement versus repair: propensity-adjusted survival and quality-of-life analysis. Ann Thorac Surg 84:451-8.

Kuntze T, Borger MA, Falk V, et al. 2008. Early and mid-term results of mitral valve repair using premeasured Gore-Tex loops ('loop technique'). Eur J Cardiothoracic Surg 33:566-72.

Mohty D, Orszulak TA, Schaff HV, Avierinos JF, Tajik JA, EnriquezSarano M. 2001. Very long-term survival and durability of mitral valve repair for mitral valve prolapse. Circulation 104(12 suppl 1):I1-7.

Morimoto H, Tsuchiya K, Nakajima M, Akashi O. 2008. Mitral valve repair for anterior leaflet prolapse: surgical techniques review and 16-year follow-up results. J Card Surg 23:426-30.
Okada Y, Nasu M, Koyama T, et al. 2012. Outcomes of mitral valve repair for bileaflet prolapse. J Thorac Cardiovasc Surg 143(4 suppl):S21-3.

Phillips MR, Daly RC, Schaff HV, Dearani JA, Mullany CJ, Orszulak TA. 2000. Repair of anterior leaflet mitral valve prolapse: chordal replacement versus chordal shortening. Ann Thorac Surg 69:25-9.

Sand ME, Naftel DC, Blackstone EH, Kirklin JW, Karp RB. 1987. A comparison of repair and replacement for mitral valve incompetence. J Thorac Cardiovasc Surg 94:208-19.

Smedira NG, Selman R, Cosgrove DM, et al. 1996. Repair of anterior leaflet prolapse: chordal transfer is superior to chordal shortening. J Thorac Cardiovasc Surg 112:287-91; discussion 291-2.

Zoghbi WA, Enriquez-Sarano M, Foster E, et al. 2003. Recommendations for evaluation of the severity of native valvular regurgitation with two-dimensional and Doppler echocardiography. J Am Soc Echocardiogr 16:777-802. 